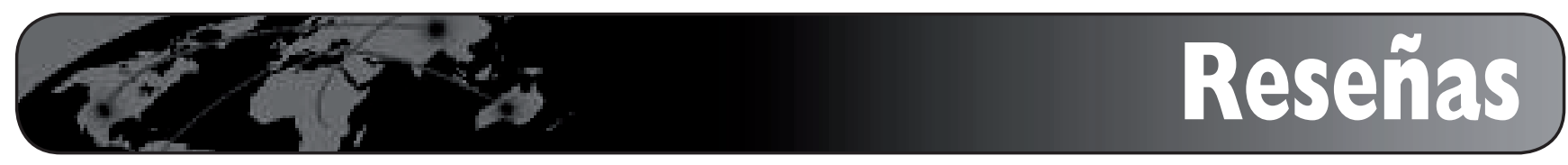

\title{
Manual de indización: teoría y práctica (Isidoro Gil-Leiva)
}

\author{
Por Adolfo Alonso-Arroyo
}

\begin{abstract}
Alonso-Arroyo, Adolfo. "Manual de indización: teoría y práctica (Isidoro Gil-Leiva)". (Reseña de libro). El profesional de la información, 2009, septiembre-octubre, v. 18, n. 5, pp. 567-568.

DOI: $10.3145 /$ epi.2009.sep.13
\end{abstract}

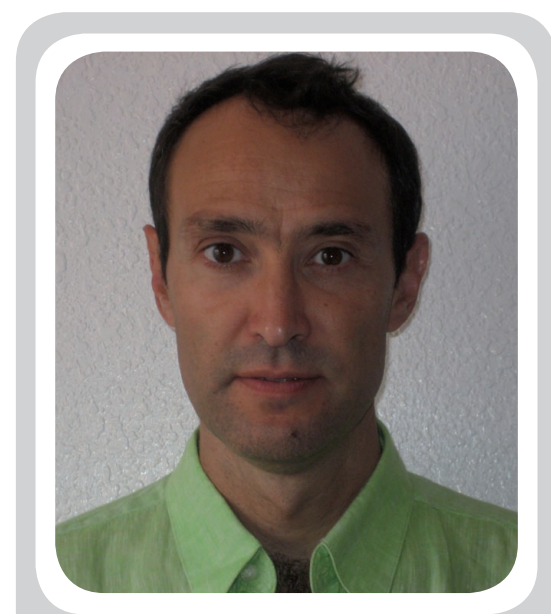

Isidoro Gil-Leiva es diplomado en biblioteconomía y documentación, licenciado en geografía e historia y doctor desde 1997 con una tesis sobre indización automática. Es profesor titular en la Universidad de Murcia. En 1999 publica el libro "La automatización de la indización de documentos" y como editor ha preparado las I Jornadas de Tratamiento y Recuperación de Información (2002). También ha publicado numerosos artículos sobre indización en revistas nacionales e internacionales. Ha impartido conferencias y cursos sobre indización y ha realizado estancias docentes y de investigación en Costa Rica, Uruguay y Brasil. Durante 2008 y 2009 ha visitado diferentes archivos y bibliotecas nacionales en el marco de un proyecto de investigación sobre políticas de indización en Latinoamérica.

http://webs.um.es/isgil
SIGUIENDO EN LA LÍNEA DE SU ANTERIOR TRABAJO, La automatización de la indización de documentos (Trea, 1999), el autor ha concebido este manual como un material básico para profesionales de la información, investigadores, profesores $\mathbf{y}$ alumnos, así como para aquellas personas que se están iniciando en este campo del saber.

En su redacción se ha utilizado un cuidadoso estilo, con un lenguaje sencillo pero riguroso, bien estructurado, lejos de tecnicismos y complicadas explicaciones teóricas.

El manual está dividido en 6 capítulos bien diferenciados pero a su vez entrelazados entre sí, con múltiples ejemplos intercalados en el texto que aclaran la teoría en cada momento y lo convierten en un manual muy dinámico. Así mismo, con el fin de no desviar al lector del tema central, se introducen alertas gráficas para reforzar y resaltar los aspectos más significativos.

En el primer capítulo titulado "El proceso cognitivo de indización" se explica cómo el indizador necesita de un proceso cognitivo basado en la percepción sensorial (memoria) de la información y en la organización de la comunicación mediante la información para identificar y seleccionar palabras clave, términos de indización o la asigna-

"Cabe resaltar el epígrafe dedicado a las políticas de indización llevadas a cabo por algunas instituciones

en sus bases de datos documentales"

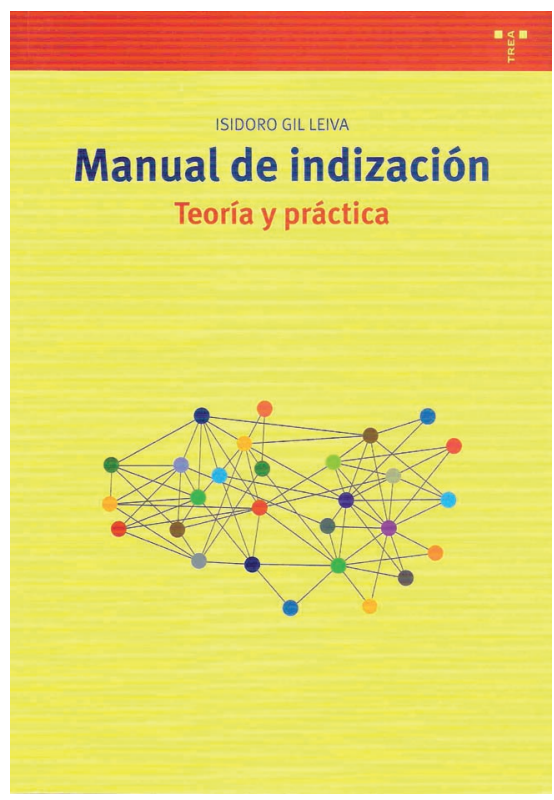

Gil-Leiva, Isidoro. Manual de indización: teoría y práctica. Gijón: Trea, 2008, 432 p. (Biblioteca y administración cultural; 193).

ISBN 978-84-9704-367-0.

ción de encabezamientos de materia. Se presentan aspectos relativos a la lectura como piedra angular de la indización.

El segundo capítulo se adentra de lleno en el proceso técnico documental y en concreto en la indización. Se comienza integrando la indización dentro de este proceso para continuar diferenciando entre la indización y el índice. Se examinan la exhaustividad, precisión, corrección y consistencia como cua- 
lidades que caracterizan el proceso de indización.

La distinción entre el lenguaje natural y el lenguaje controlado se desgrana en el tercer capítulo con el fin de mostrar las herramientas propias de cada uno, tales como listas de palabras clave, listas de descriptores, listas de encabezamientos de materias y tesauros, que a su vez irán acompañadas de múltiples ejemplos que permiten al lector conocer en detalle las características propias de cada una.

El siguiente capítulo completa el anterior, al presentar la indización con lenguaje natural y controlado mediante casos prácticos, utilizando para ello una completa casuística de tipos documentales. Cabe resaltar el epígrafe dedicado a las políticas de indización llevadas a cabo por algunas instituciones en sus bases de datos documentales. Termina el capítulo con un decálogo de la indización (pág. 317) en el que se recopilan los conocimientos teóricos y prácticos mostrados en esta primera

\section{"Sisa es el nombre que recibe el prototipo de sistema de indización semiautomática creado por el autor"}

parte, necesarios para adentrarse en el próximo capítulo dedicado a la indización automática.

Analiza la automatización de la indización como una técnica interdisciplinar que necesita del aporte de la lingüística, terminología, informática, lingüística computacional y estadística, y expone las herramientas a utilizar en un sistema de indización automática, que se pueden clasificar en estadísticas, linguiísticas o mixtas. Como colofón a este apartado, el autor da a conocer los principales elementos y las características de diseño de Sisa, nombre que recibe el prototipo de sistema de indización semiautomática creado por él mismo.

En el último capítulo, dedicado a la evaluación de la indización, el autor comenta la evaluación intrínseca y extrínseca como dos formas diferentes de valorar la indización. En la intrínseca se toma en consideración el contenido en sí mismo; ésta puede ser cualitativa, mediante el análisis por especialistas, o cuantitativa, basada en factores de medición. En la extrínseca se valora la indización por los efectos que produce comparando sistemas de información.

El manual se complementa con una extensa bibliografía actualizada pero sin olvidar la mención a los autores clásicos. Se distribuye en capítulos y en cada uno se recoge una parte general y una especializada para los que deseen profundizar en cada uno de los aspectos tratados.

\section{"Es una buena guía para los estudios sobre indización y su avance hacia la indización automática"}

Por todo ello, esta obra es una guía muy interesante para los estudios sobre indización y su avance hacia la indización automática. El autor muestra un amplio conocimiento de este tema, lo que unido a su habilidad redactora y a su destreza en fusionar los conocimientos teóricos y prácticos, facilita la lectura y mantiene el interés del lector pese a tratarse de un contenido técnico que en ocasiones pudiera resultar poco atrayente.

Adolfo Alonso-Arroyo. Facultat de Medicina $i$ Odontologia, Departament d'Història de la Ciència i Documentació, Universitat de València. Avda. Blasco Ibáñez 15, 46010 Valencia.

adolfo.alonso@uv.es

\section{Próximos temas centrales}

Noviembre 2009

Enero 2010

Marzo 2010

Mayo 2010

Julio 2010

Septiembre 2010

Noviembre 2010
Servicios y sistemas de referencia digital

Sector editorial

Publicidad y comunicación empresarial

Información bio-médica

Arquitectura de la información

Cooperación de bibliotecas en red

Medios de comunicación en internet

Los interesados pueden remitir notas, artículos, propuestas, publicidad, comentarios, etc., sobre estos temas a: http://recyt.fecyt.es/index.php/EPI/index 